\title{
Conditional responses to increasing scales of disturbance, and potential implications for threshold dynamics in soft-sediment communities
}

\author{
Joanna Norkko ${ }^{1,2,3, *}$, Alf Norkko ${ }^{1,2,4}$, Simon F. Thrush ${ }^{5,6}$, Sebastian Valanko ${ }^{1,2,3}$, \\ Heli Suurkuukka ${ }^{7}$
}

\author{
${ }^{1}$ Marine Research Centre, Finnish Environment Institute, PO Box 140, 00251 Helsinki, Finland \\ ${ }^{2}$ Tvärminne Zoological Station, 10900 Hanko, Finland \\ ${ }^{3}$ Environmental and Marine Biology, Åbo Akademi University, Artillerigatan 6, 20520 Åbo, Finland \\ ${ }^{4}$ Department of Marine Ecology - Kristineberg, University of Gothenburg, 45034 Fiskebäckskil, Sweden \\ ${ }^{5}$ National Institute of Water and Atmospheric Research, PO Box 11-115, Hamilton, New Zealand \\ ${ }^{6}$ DipTeRis, University of Genoa, Corso Europa 26, 16132 Genoa, Italy \\ ${ }^{7}$ Department of Biology, University of Oulu, PO Box 3000, 90014 Oulu, Finland
}

\begin{abstract}
Disturbance-recovery experiments conducted across environmental gradients can reveal the relative importance of processes, feedbacks and threshold conditions that sustain ecosystem functioning and resilience. In the present paper we argue that threshold responses to disturbance (e.g. marked non-linear shifts in abundance of important species) are scale-, context- and speciesdependent. In order to test the context-dependency in recovery dynamics of soft-sediment benthic communities, we conducted a large-scale sublittoral experiment investigating patterns in recovery of 2 functionally different groups of deposit feeders (surface vs. subsurface deposit feeders; Hydrobiidae vs. Oligochaeta) with increasing spatial scales of hypoxic disturbance in the Baltic Sea. Plots $\left(1,4\right.$ and $\left.16 \mathrm{~m}^{2}\right)$ were defaunated at 4 sandy sites $(5 \mathrm{~m} \mathrm{depth})$ that varied in exposure to wind-waves, and subsequent recovery of macrofaunal abundances was monitored over $15 \mathrm{mo}$, focusing on postlarval recolonisation. Recovery patterns were site-specific, depended on the scale of disturbance, and indicated a shift in the relative importance of smaller-scale biological factors to broader-scale physical factors, i.e. waves, currents and sediment transport, when moving from sheltered to more exposed sites. We found group-specific responses, related to mode of living (epifaunal/infaunal) and dispersal potential. In addition, Hydrobiidae exhibited opportunistic population increases in response to disturbance, likely due to increased food availability. The results highlight the importance of interactions between environmental factors, and understanding natural-history characteristics and relative mobility of different taxa, when assessing both the resilience and the recovery of benthic communities.
\end{abstract}

KEY WORDS: Disturbance $\cdot$ Conditional recovery patterns $\cdot$ Scale $\cdot$ Soft-sediment communities Opportunistic responses $\cdot$ Food availability

\section{INTRODUCTION}

Abrupt changes in ecosystem qualities can occur as a result of extreme environmental forcing, as a consequence of changing intrinsic dynamics or the interaction of factors (Groffman et al. 2006, Scheffer et al. 2009, Swift \& Hannon 2010). Soft-sediment habitats are often considered disturbance-dominated systems and recovery rates and patterns may provide important insights into the potential for broad-scale and abrupt changes in the structure and function of benthic communities. For example, theoretical predictions show that rates of recovery from small-scale perturbation could indicate how close to a threshold a system is (van 
Nes \& Scheffer 2007, Scheffer et al. 2009). Changes in spatial structure across landscapes can affect connectivity and local recovery that produce broad-scale changes in community structure (Pascual \& Guichard 2005), and field studies of benthic communities show that following disturbance, the rates and patterns of recovery are both scale-dependent and influenced by site-specific environmental factors (Zajac et al. 1998, Thrush et al. 2003). In addition, faunal responses to disturbance are species-specific, with the potential for opportunistic population increases in response to release of available food resources or release from predation or competition pressure (Norkko et al. 2006b, Van Colen et al. 2008). Thus disturbance-recovery experiments can reveal processes, feedbacks and threshold conditions that are important for ecosystem resilience and can thus provide important insights into the functioning and appropriate management of ecosystems (Thrush et al. 2009).

Knowledge of natural history and the role of particular types of organisms in the ecosystem is critical for predicting species- and species-environment interactions that could lead to threshold responses (Dayton 2003). Aggregation, patchiness and the spatial distribution of a population may provide information on the mechanisms structuring the population, as these patterns are modified by both biotic and abiotic factors (Thrush 1991). Density-dependent shifts in speciesinteraction strength, direction and feedback are likely to influence recovery patterns and community dynamics after disturbance. For example, species may aggregate around patchy food resources released by the disturbance and then change their degree of aggregation during recovery (Norkko \& Bonsdorff 1996a, Norkko et al. 2006b).

In soft-sediment communities, dispersal is a key process, often involving many different life stages, with different dispersal scales and mechanisms (Whitlatch et al. 1998), highlighting the need to include demographics in studies of disturbance and recovery. Depending on the mode of colonisation (e.g. largescale settlement of pelagic larvae, post-settlement dispersal with sediment bedload transport, or adult crawling/swimming), if the size of disturbed patches exceeds the scales of dispersal of specific species, then the system may be predisposed to tip into an opportunism-dominated community state. However, in marine systems many details of dispersal and colonisation are relatively poorly known (Cowen \& Sponaugle 2009). Nevertheless, dispersal potential is dependent on both species' and habitat characteristics; for example, Valanko et al. (2010) showed that in non-tidal areas, infaunal species are less likely to disperse with sediment bedload transport compared with epifaunal species.
Species with strong functional roles that may influence resource availability in recovering patches, but that are also affected by environmental forces (Norkko et al. 2006a), are likely to exhibit scale-dependent responses important in maintaining ecological resilience (Thrush et al. 2009). In a species-poor ecosystem with low levels of functional diversity and complementarity, once a threshold that reflects the sensitivity of a functional group or taxon to a stressor is passed then major changes in recovery dynamics and ecosystem function are to be expected. For example, in the Baltic Sea, feedback loops between degraded benthic communities, hypoxia and internal nutrient loading from the sediments are implicated in the continued large-scale eutrophication of the ecosystem (Karlson et al. 2007, Vahtera et al. 2007).

As species-environment relationships are likely to change across larger-scale gradients in environmental factors (e.g. wave exposure, salinity, nutrient status), experiments should be conducted across environmental stress gradients to improve predictive capacity and to disentangle the combined effects of humaninduced and natural stress factors (Hewitt et al. 2007, Thrush et al. 2009). In sublittoral habitats, large-scale experiments conducted across gradients of environmental variables are rare and much of our current knowledge about disturbance-recovery dynamics in soft-sediment communities stems from manipulative experiments in intertidal areas (Thrush et al. 1996, Norkko et al. 2006b, Van Colen et al. 2008, although see Zajac \& Whitlatch 1982 for a shallow subtidal study) or before-after sampling efforts in relation to dredging or other large-scale impacts (Dauer \& Simon 1976, Pearson \& Rosenberg 1978). Therefore the scale-dependence and relative importance of ecological mechanisms and processes in sublittoral, coastal systems deserves additional attention. In this context, experiments conducted over multiple sites will facilitate assessment of the relative importance of broad-scale environmental patterns and small-scale mechanisms, and enhance the generality of the findings, which is crucial for our ability to predict change (Thrush et al. 2000).

In the present paper we highlight the importance of considering the context-dependency of threshold dynamics in light of disturbance-recovery ecology. If the disturbance approaches or exceeds some threshold level, the benthic community may exhibit a threshold response (i.e. marked non-linear shifts in abundance, diverging recovery trajectories and/or changes in interactions between important species). More specifically we argue that such changes in system dynamics are scale-, context- and species-dependent. The critical disturbance size may be site-dependent due to interactions with the physical characteristics of a site 
(e.g. currents, waves, sediment grain size characteristics) and dependent on the timing of disturbance in relation to seasonal recruitment patterns, with potentially profound implications for subsequent community assembly. Changes in recovery dynamics may thus indicate that the disturbance has exceeded a threshold level.

We designed a sublittoral disturbance-recovery experiment to investigate patterns in the recovery of macrofaunal abundances after increasing spatial scales of hypoxic disturbance, focusing on post-larval recolonisation. Recovery was assessed in terms of abundances and size-frequency distributions in relation to natural seasonal fluctuations in undisturbed control areas. The experiment was conducted at 4 sublittoral sites that represent gradients of increasing exposure to windwaves (the major hydrodynamic force in our studied system) and increasing sediment grain size. We focused our analysis on the 2 numerically dominant groups of deposit feeders: hydrobid mudsnails that are mobile as adults and live on the sediment surface versus infaunal oligochaetes with limited larval dispersal and comparatively more sedentary adult stages. Both groups have the potential to utilise food resources released by the disturbance. The following predictions were tested:

(1) Recovery was predicted to be faster at more exposed sites, where currents and wave-action aid the dispersal of fauna into the disturbed area.

(2) Recovery was predicted to depend on the scale of disturbance and to be faster in smaller disturbed areas.

(3) Recovery was predicted to be faster in mobile epifauna, compared with infauna.

(4) Recovery mechanisms were predicted to differ between the 2 taxonomic groups and the relative importance of these mechanisms was predicted to change across the environmental gradients in the study area.

The results of the 15 mo experiment were analysed with emphasis on the interactions between natural-history characteristics in these contrasting deposit-feeders and environmental site-specific variables such as sediment characteristics and wave exposure. Thus, the aim was to provide insight into the recovery dynamics for important deposit-feeders in soft-sediment systems. By understanding context-dependent shifts in the recovery processes, we may more generally predict threshold responses.

\section{MATERIALS AND METHODS}

Study area. The field experiment was conducted in the northern Baltic Sea, in the outer archipelago near Tvärminne Zoological Station (59 50' N, 2314' E), Finland (Fig. 1). Four coastal sites 1 to $5 \mathrm{~km}$ apart were chosen to encompass a range of exposure to windwaves, with exposure increasing from Sites A to D. Salinity is around 6 and there are no tides in the area. All sites were at about $5 \mathrm{~m}$ depth and had sandy sediments (organic content $<1 \%$ ), with a range in grain size corresponding to the wave climate and exposure at each site (see Table 1). Macrofaunal communities were dominated by typical brackish water taxa such as

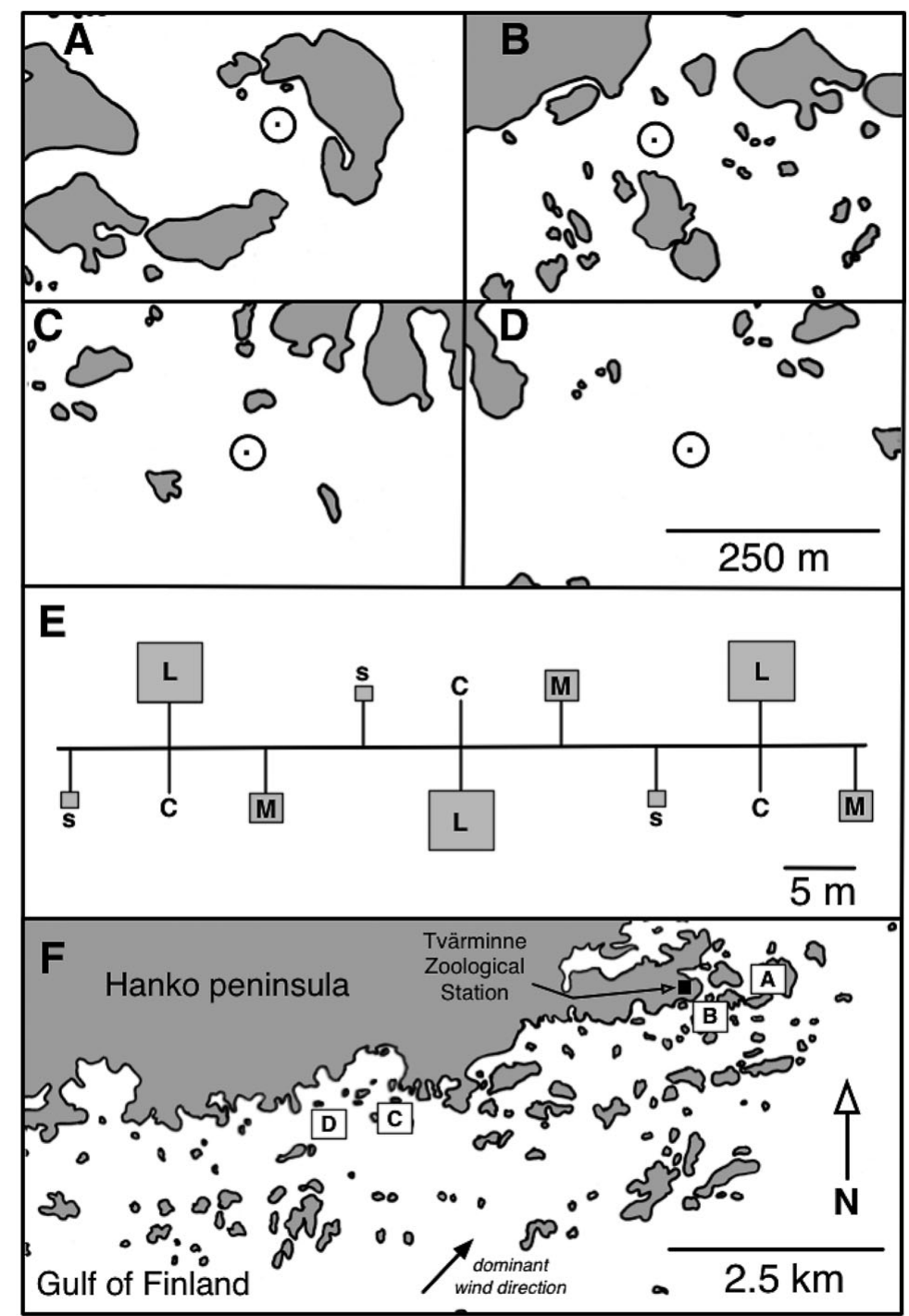

Fig. 1. (A-D) Location of study Sites $A$ to $D_{i}$ (E) experimental design employed at each site, with arrangement of plots along $50 \mathrm{~m}$ transect at each site, where $\mathrm{C}=$ Control, $\mathrm{S}=$ Small, $\mathrm{M}=$ Medium and $\mathrm{L}=$ Large, corresponding to $0,1,4$ and $16 \mathrm{~m}^{2}$ disturbance plots respectively; and (F) position of study sites in relation to one another off southwestern Finland. Wind-wave exposure increases from Sites A to D 
oligochaetes, the hydrobid mudsnails Hydrobia ulvae and Potamopyrgus antipodarum, the bivalve Macoma balthica, and the polychaetes Hediste diversicolor and Marenzelleria sp.

Experimental setup. The disturbance experiment simulated patchy coastal hypoxia induced, for example, by drifting algal mats (Norkko \& Bonsdorff 1996a, 1996b). Hypoxic disturbance was initiated by covering experimental plots with plastic, and all manipulations and sampling were done using SCUBA. At each site, disturbance plots of 1,4 and $16 \mathrm{~m}^{2}$ and control plots (hereinafter referred to as Small, Medium, Large and Control) were each replicated 3 times (Fig. 1). The location of different treatment replicates was stratified along a $50 \mathrm{~m}$ transect to ensure that potential underlying spatial patterns of fauna or environmental factors, not visible from the sediment surface, would not affect the interpretation of recolonisation patterns. The plots were defaunated by covering the sediment surface with black low-density polyethylene (LDPE) plastic to induce anoxia to underlying sediments. The edges of the plastic sheets were held in place with metal rods secured with $30 \mathrm{~cm}$ metal pegs, which prohibited any water exchange from underneath the plastic. Plots were covered for a $16 \mathrm{~d}$ period to ensure complete defaunation and the experiment started by carefully removing the plastic in late July.

Macrofauna. After defaunation, macrofaunal community data was collected from defaunated and control plots to track faunal recovery dynamics over 15 mo, focusing on post-larval recolonisation, but also including the peak in seasonal recruitment the year after the disturbance (all sites sampled at 0, 0.5, 1, 3, 10, 12 and 15 mo, with time 0 corresponding to 31 July 2006). Three replicate cores (diameter $5.6 \mathrm{~cm}$, depth $15 \mathrm{~cm}$ ) were taken within a central area $\left(0.25 \mathrm{~m}^{2}\right)$ of each plot on each sampling occasion. Cores were never taken from the same exact location within this central plot area over the course of the experiment. Sediment bedload traps were used to compare relative dispersal rates for Hydrobiidae and Oligochaeta in Control and Large plots (see Valanko et al. 2010). Traps were not deployed in the Small and Medium plots, as they might have introduced a relatively large artefact in these plots. The traps (diameter $3.7 \mathrm{~cm}$, depth $29 \mathrm{~cm}$, aspect ratio 7.8:1) were slotted into pre-deployed outer sleeves, flush with the sediment surface. At each site a total of 5 traps were deployed in the Control areas (1 near each of the 3 Control plots +2 extra), while 1 trap was deployed in the centre of each Large plot (i.e. 3 per site). The traps were deployed for $48 \mathrm{~h}$ at each site on each sampling occasion.

The core and trap samples were preserved in $70 \%$ ethanol and stained with Rose Bengal before enumeration of all macrofaunal taxa. To include small recruits, the samples were elutriated by first suspending the sediment in a bucket of spinning water and decanting off the supernatant through a $200 \mu \mathrm{m}$ sieve (repeated 5 times), and then checking the remaining sediment for any larger animals.

We focused on the recovery patterns of 2 key taxa, Hydrobiidae and Oligochaeta. Hydrobiidae are surface detritivores/grazers that actively crawl on the sediment surface. In contrast, Oligochaeta are burrowing detritivores. Hydrobia ulvae veligers may be planktonic, while $H$. ventrosa do not have planktonic larvae. The Oligochaeta considered here produce egg capsules that hatch without a planktonic stage. In order to focus on the recolonisation by post-settlement and adult stages, the experiment was started after the major seasonal peak in settlement for both groups. The abundance of the mudsnails $H$. ulvae, $H$. ventrosa, and Potamopyrgus antipodarum was pooled (hereinafter collectively referred to as Hydrobiidae). H. ulvae was the dominant mudsnail at all sites throughout the study. $P$. antipodarum contributed about $5 \%$ at Site A and 10 to $40 \%$ at the other sites. H. ventrosa contributed $<1 \%$ at all sites. Oligochaeta were not identified to species level. However, tubificid oligochaetes such as Clitellio arenarius and Limnodrilus sp. typically dominate shallow sandy habitats in the northern Baltic Sea.

Sediment properties. As a measure of food available to near-surface deposit feeders, sediment chlorophyll a (chl a) samples were taken from each plot on each sampling occasion with a $2.1 \mathrm{~cm}$ diameter core. The top $1 \mathrm{~cm}$ of sediment was sliced off the cores, stored at $-20^{\circ} \mathrm{C}$ and freeze-dried prior to analysis. Chl a was extracted from sediments in $90 \%$ acetone for $24 \mathrm{~h}$ and measured spectrophotometrically. An acidification step was included to separate degradation products from chl a (Sartory 1982).

Sediment grain size was measured from 5 replicate core samples (diameter $2.1 \mathrm{~cm}$, depth $5.0 \mathrm{~cm}$ ) collected once from each site in undisturbed areas. Hydrogen peroxide $(6 \%)$ was used to dissolve organic material. Grain sizes were separated into $<63,63-250,250-500$ and $>500 \mu \mathrm{m}$ fractions using respective sieves and dry weight was obtained for each fraction $\left(48 \mathrm{~h}\right.$ at $\left.60^{\circ} \mathrm{C}\right)$.

Stable isotope analysis of Hydrobia ulvae and sediment. In order to investigate whether recolonisation patterns of $H$. ulvae over different spatial and temporal scales could be linked to food availability, stable isotopes of carbon and nitrogen $\left(\delta^{13} \mathrm{C}\right.$ and $\left.\delta^{15} \mathrm{~N}\right)$ of surface sediments and $H$. ulvae were measured on 4 different occasions at Site A, the most sheltered site. This site was targeted as it had the highest abundance of Hydrobiidae. Sediment samples were obtained from each plot with a $2.1 \mathrm{~cm}$ diameter core. H. ulvae were hand-picked by divers from each plot using a pipette 
(10 adult individuals pooled per plot). All individuals were identified live under the microscope and only adults of the numerically dominant $H$. ulvae were included in the analyses. The mudsnails were left in filtered seawater for $3 \mathrm{~h}$ to empty their guts and were then dried at $60^{\circ} \mathrm{C}$ for $48 \mathrm{~h}$. To remove carbonates from the shells, the crushed samples were acidified in $2 \mathrm{~N}$ $\mathrm{HCl}$ (Herman et al. 2000). After the acid was removed with a pipette, the homogenate was rinsed with distilled water and dried at $60^{\circ} \mathrm{C}$ overnight. The sample was re-homogenised and $1 \mathrm{mg}$ weighed into a tin capsule for analysis. For analysis of sediment stable isotope signatures, the top $0.5 \mathrm{~cm}$ of the sediment was sliced off and dried at $60^{\circ} \mathrm{C}$ for $48 \mathrm{~h}$. The sediment was ground to a fine powder and passed through a $500 \mu \mathrm{m}$ sieve to remove coarse sand. A subsample was acidified with 2 drops of $1 \mathrm{~N} \mathrm{HCl}$ and dried at $60^{\circ} \mathrm{C}$ overnight. The sample was re-homogenised and $30 \mathrm{mg}$ weighed into a tin capsule for analysis.

Stable isotopes of Hydrobia ulvae were analysed at the Institute for Environmental Research, University of Jyväskylä, using a FlashEA 1112 elemental analyser coupled to a Thermo Finnigan DELTA ${ }^{\text {plus }}$ Advantage mass spectrometer (Thermo Electron). Sediments were analysed at the University of California Davis Stable Isotope Facility, using a PDZ Europa ANCA-GSL elemental analyser coupled to a PDZ Europa 20-20 mass spectrometer (Sercon). In both cases, PDB limestone and atmospheric nitrogen were used as standards for $\delta^{13} \mathrm{C}$ and $\delta^{15} \mathrm{~N}$, respectively. Isotopic ratios, expressed in delta $(\delta)$ notation, were calculated relative to the standards using the formula:

$$
\begin{gathered}
\delta^{13} \mathrm{C} \text { or } \delta^{15} \mathrm{~N}(\%)=\left[\left(R_{\text {sample }} / R_{\text {standard }}\right)-1\right] \times 10^{3} ; \\
\text { where } R={ }^{13} \mathrm{C} /{ }^{12} \mathrm{C} \text { or }{ }^{15} \mathrm{~N} /{ }^{14} \mathrm{~N}
\end{gathered}
$$

Data analysis. Two-way ANOVA was used to analyse treatment-related differences in sediment chl a within each site over the first 3 mo of the experiment. Treatment and sampling time were treated as fixed factors because we chose scales of disturbance to encompass different adult mobility scales of resident organisms and dates to reflect specific times in the strong seasonal cycle in the Baltic. One-way ANOVA was used to analyse general differences in sediment chl a between sites over the first 3 mo of the experiment (data from Control plots only, all times pooled). Prior to ANOVA analyses, data were examined for homogeneity of variances (Levene's) and normality (Kolmogorov-Smirnov). Initial analyses of abundances of Hydrobiidae and Oligochaeta across treatments, sites and times (fixed factors) were performed within a generalised linear modelling framework (McCullagh \& Nelder 1989, Crawley 1993). Preliminary inspection of abundance patterns over time in the experimental plots revealed that recovery was not consistent across sites (as expected) and further analyses of recovery and treatment effects were done on a site-by-site basis. Variance-to-mean ratios were used as a measure of spatial aggregation of Hydrobiidae and Oligochaeta in different treatments at different sites over time. Kolmogorov-Smirnov 2-sample tests were used to compare size frequency distributions in Hydrobiidae between sites and treatments. Relative dispersal rates were calculated for Hydrobiidae and Oligochaeta from number of individuals caught in a trap per day divided by number of individuals in corresponding cores, i.e. traps in Control plots divided by densities in Control cores and traps in Large plots divided by densities in cores from the same Large plots (in this non-tidal system, animals at $5 \mathrm{~m}$ depth were unlikely to passively move $>2 \mathrm{~m}$ over the $48 \mathrm{~h}$ trap deployments, which occurred under relatively calm wind conditions). Twoway ANOVA with treatment and sampling time as fixed factors was used to test differences in relative dispersal for the 2 taxa separately, after testing the assumptions of homogeneity of variances and normality. Linear regression was used to analyse trends in stable isotope signatures of Hydrobia ulvae and sediment across different-sized disturbed plots.

\section{RESULTS}

\section{Visual observations and sediment chl a}

Defaunation was successful at all sites. The sediment underneath the plastic sheets was black all the way to the plot edges, with large numbers of dead or moribund adult bivalves (mainly Macoma balthica and Mya arenaria) and polychaetes (mainly Hediste diversicolor and Marenzelleria sp.) on the sediment surface. These specimens were gone within 1 to $2 \mathrm{~d}$, indicating that this very transient additional food resource was efficiently utilised by fish (Platichthys flesus and Perca fluviatilis) observed near the plots immediately after removal of the plastic.

Two weeks after the disturbance, the disturbed plots were visibly greener than the control plots at all sites, indicating fast growth of microphytobenthos. This pattern was still noticeable the following spring, $10 \mathrm{mo}$ after the disturbance. Despite the obvious growth of microalgae, no significant treatment effects were detected in the sediment chl a values at any of the sites over the first 3 mo of the recovery (2-way ANOVAs, $p>0.05$, data not shown). This is probably because the sample integrated chl a over the top $1 \mathrm{~cm}$ of the sediment, instead of targeting only the very top sediment surface, where the microalgae are most abundant. The greener appearance in the disturbed plots was likely due to a combination of higher amounts of available 
sediment nutrients and lower rates of bioturbation and grazing in these plots compared with the Control plots, resulting in more microphytobenthos remaining in the top millimetres of the sediment surface. Although no differences were found between treatments at any of the sites, there were clear differences in the general levels of sediment chl a between the respective sites (Control plots, 1-way ANOVA: $F_{3,35}=49.58$, $\mathrm{p}<0.001$; Table 1), with the lowest levels at Sites A and $\mathrm{D}$, and the highest levels at Sites B and C.

\section{Site- and taxon-dependent recovery patterns}

Patterns of recovery after anoxia differed between sites, between scales of disturbance, and also between
Table 1. Environmental characteristics at the experimental sites. Sediment grain size fractions and median grain size refer to the top $5 \mathrm{~cm}$ of the sediment $(\mathrm{n}=5)$. Sediment (Sed.) chl $a$ is the average $( \pm \mathrm{SD}, \mathrm{n}=9$ ) of the top $1 \mathrm{~cm}$ in Control plots in July to October of the first year of the study

\begin{tabular}{|c|c|c|c|c|c|c|}
\hline \multirow[t]{2}{*}{ Site } & \multirow{2}{*}{$\begin{array}{c}\text { Silt and } \\
\text { clay } \\
(<63 \mu \mathrm{m})\end{array}$} & \multicolumn{3}{|c|}{ Sediment grain size ( $\%$ dry wt) } & \multirow{2}{*}{$\begin{array}{c}\text { Median } \\
\text { grain size, } \\
d_{50}(\mathrm{~mm})\end{array}$} & \multirow{2}{*}{$\begin{array}{c}\text { Sed. chl } a \\
\left(\mu g g^{-1} \text { dry wt) }\right.\end{array}$} \\
\hline & & $\begin{array}{l}\text { Fine to very } \\
\text { fine sand } \\
(63-250 \mu \mathrm{m})\end{array}$ & $\begin{array}{c}\text { Medium } \\
\text { sand } \\
(250-500 \mu \mathrm{m})\end{array}$ & $\begin{array}{l}\text { Coarse } \\
\text { sand } \\
(>500 \mu \mathrm{m})\end{array}$ & & \\
\hline A & 6.6 & 78.3 & 12.0 & 3.1 & 0.14 & $11.4 \pm 0.5$ \\
\hline B & 1.8 & 36.5 & 58.0 & 3.6 & 0.29 & $23.6 \pm 1.0$ \\
\hline $\mathrm{C}$ & 0.8 & 28.4 & 33.6 & 37.2 & 0.39 & $19.6 \pm 3.2$ \\
\hline D & 0.4 & 8.8 & 35.6 & 55.2 & 0.60 & $14.1 \pm 2.4$ \\
\hline
\end{tabular}

Hydrobiidae and Oligochaeta (Table 2, Fig. 2). Abundances varied between sites and over the duration of the experiment also in the Control plots (Table 2). Analysis of abundance patterns for Hydrobiidae and Oligochaeta clearly indicated that the results of the experimental treatments were site-dependent. Significant interactions between Treatment and Sites, and Treatment and Time nested within Site were also

Table 2. Abundances of Hydrobiidae and Oligochaeta (ind. core ${ }^{-1}$, diam. $5.6 \mathrm{~cm}$ ) per site, months after disturbance and disturbance treatment (mean $\pm \mathrm{SE}, \mathrm{n}=9$ ). Months after disturbance correspond to the following dates: $0=31 \mathrm{Jul} 2006$, $0.5=12$ Aug 2006, 1 = 29 Aug 2006, $3=17$ Oct 2006, $10=9$ May 2007, $12=25$ Jul 2007 and $15=9$ Oct 2007. Small = $1 \mathrm{~m}^{2}, \mathrm{Medium}^{2} 4 \mathrm{~m}^{2}$, Large $=16 \mathrm{~m}^{2}$. Wind-wave exposure increases from Sites A to D

\begin{tabular}{|c|c|c|c|c|c|c|c|c|c|}
\hline \multirow[t]{2}{*}{ Site } & \multirow[t]{2}{*}{ Month } & \multicolumn{4}{|c|}{$\longrightarrow$ Hydrobiidae $\longrightarrow$} & \multicolumn{4}{|c|}{ - Oligochaeta } \\
\hline & & Control & Small & Medium & Large & Control & Small & Medium & Large \\
\hline \multirow[t]{7}{*}{ A } & 0 & $4.1 \pm 0.9$ & 0 & 0 & 0 & $11.8 \pm 3.0$ & 0 & 0 & 0 \\
\hline & 0.5 & $5.3 \pm 1.1$ & $4.9 \pm 1.2$ & $3.4 \pm 1.0$ & $1.3 \pm 0.4$ & $8.6 \pm 2.6$ & $4.8 \pm 1.0$ & $4.9 \pm 1.0$ & $2.4 \pm 0.6$ \\
\hline & 1 & $8.1 \pm 1.5$ & $17.3 \pm 2.4$ & $14.7 \pm 3.1$ & $16.1 \pm 1.8$ & $13.7 \pm 1.9$ & $6.7 \pm 1.2$ & $10.0 \pm 1.5$ & $5.0 \pm 0.9$ \\
\hline & 3 & $16.1 \pm 2.4$ & $17.1 \pm 2.0$ & $29.7 \pm 3.3$ & $24.0 \pm 2.9$ & $24.0 \pm 2.5$ & $15.7 \pm 1.5$ & $15.6 \pm 2.3$ & $21.0 \pm 3.2$ \\
\hline & 10 & $6.2 \pm 0.7$ & $19.7 \pm 4.2$ & $15.9 \pm 2.3$ & $24.7 \pm 5.0$ & $7.0 \pm 1.3$ & $10.2 \pm 2.0$ & $10.1 \pm 2.1$ & $13.9 \pm 2.7$ \\
\hline & 12 & $10.6 \pm 1.9$ & $18.7 \pm 4.0$ & $18.2 \pm 2.5$ & $23.0 \pm 2.4$ & $7.3 \pm 1.2$ & $10.7 \pm 1.4$ & $6.1 \pm 1.2$ & $3.0 \pm 0.4$ \\
\hline & 15 & $10.1 \pm 1.4$ & $10.7 \pm 1.3$ & $10.3 \pm 1.6$ & $10.3 \pm 1.0$ & $10.2 \pm 1.7$ & $10.6 \pm 1.5$ & $7.9 \pm 1.9$ & $6.9 \pm 1.3$ \\
\hline \multirow[t]{7}{*}{ B } & 0 & $2.8 \pm 0.7$ & 0 & 0 & 0 & $14.7 \pm 2.9$ & 0 & 0 & 0 \\
\hline & 0.5 & $4.9 \pm 1.2$ & $3.6 \pm 0.9$ & $4.4 \pm 1.6$ & $4.9 \pm 1.1$ & $32.6 \pm 10.1$ & $5.1 \pm 1.2$ & $6.7 \pm 2.8$ & $10.3 \pm 3.0$ \\
\hline & 1 & $11.7 \pm 1.8$ & $12.8 \pm 3.4$ & $8.1 \pm 1.8$ & $9.2 \pm 1.8$ & $8.8 \pm 1.9$ & $6.3 \pm 2.5$ & $9.8 \pm 3.7$ & $10.1 \pm 3.4$ \\
\hline & 3 & $18.6 \pm 1.8$ & $23.2 \pm 3.3$ & $24.2 \pm 2.5$ & $21.3 \pm 2.2$ & $11.7 \pm 2.9$ & $7.1 \pm 1.1$ & $4.9 \pm 1.1$ & $8.0 \pm 1.6$ \\
\hline & 10 & $9.7 \pm 1.9$ & $17.0 \pm 4.5$ & $11.7 \pm 1.9$ & $11.0 \pm 2.4$ & $14.6 \pm 2.2$ & $7.7 \pm 1.2$ & $11.0 \pm 1.2$ & $6.6 \pm 1.4$ \\
\hline & 12 & $8.2 \pm 1.6$ & $11.2 \pm 1.5$ & $14.8 \pm 2.2$ & $9.7 \pm 1.7$ & $4.9 \pm 1.8$ & $9.3 \pm 2.4$ & $2.8 \pm 0.8$ & $7.4 \pm 2.3$ \\
\hline & 15 & $35.4 \pm 4.7$ & $35.7 \pm 4.0$ & $42.6 \pm 3.9$ & $30.3 \pm 3.3$ & $8.7 \pm 1.5$ & $9.3 \pm 1.7$ & $16.8 \pm 3.4$ & $11.6 \pm 1.6$ \\
\hline \multirow[t]{7}{*}{$\mathrm{C}$} & 0 & $3.8 \pm 0.5$ & 0 & 0 & 0 & $16.4 \pm 2.1$ & 0 & 0 & 0 \\
\hline & 0.5 & $3.4 \pm 1.0$ & $4.1 \pm 1.4$ & $3.0 \pm 0.5$ & $2.4 \pm 0.8$ & $32.1 \pm 7.3$ & $17.9 \pm 3.3$ & $30.7 \pm 2.3$ & $22.6 \pm 2.5$ \\
\hline & 1 & $5.0 \pm 0.7$ & $7.8 \pm 1.3$ & $5.7 \pm 0.8$ & $4.1 \pm 0.5$ & $35.0 \pm 10.9$ & $15.4 \pm 9.9$ & $11.9 \pm 1.5$ & $8.3 \pm 2.2$ \\
\hline & 3 & $5.4 \pm 0.6$ & $7.3 \pm 1.2$ & $10.7 \pm 1.4$ & $8.0 \pm 0.9$ & $14.1 \pm 2.8$ & $5.6 \pm 1.8$ & $3.6 \pm 0.6$ & $7.4 \pm 1.2$ \\
\hline & 10 & $6.0 \pm 1.0$ & $4.0 \pm 1.0$ & $4.7 \pm 0.7$ & $3.8 \pm 0.7$ & $16.2 \pm 4.4$ & $3.6 \pm 1.0$ & $5.9 \pm 2.1$ & $5.6 \pm 1.2$ \\
\hline & 12 & $6.7 \pm 1.2$ & $7.2 \pm 1.3$ & $9.1 \pm 1.7$ & $10.4 \pm 1.5$ & $12.9 \pm 2.8$ & $15.2 \pm 4.7$ & $11.4 \pm 3.7$ & $7.7 \pm 2.6$ \\
\hline & 15 & $23.0 \pm 2.7$ & $24.9 \pm 1.6$ & $28.3 \pm 4.9$ & $36.1 \pm 3.2$ & $27.2 \pm 6.1$ & $15.3 \pm 1.4$ & $12.1 \pm 1.9$ & $19.3 \pm 5.8$ \\
\hline \multirow[t]{7}{*}{ D } & 0 & $1.8 \pm 0.5$ & 0 & 0 & 0 & $39.3 \pm 6.8$ & 0 & 0 & 0 \\
\hline & 0.5 & $5.2 \pm 1.0$ & $4.7 \pm 0.7$ & $6.6 \pm 1.4$ & $4.8 \pm 1.0$ & $50.2 \pm 10.3$ & $28.9 \pm 7.1$ & $17.2 \pm 3.2$ & $18.7 \pm 3.4$ \\
\hline & 1 & $15.1 \pm 1.5$ & $8.6 \pm 1.0$ & $6.6 \pm 1.7$ & $7.0 \pm 1.2$ & $27.9 \pm 4.0$ & $13.1 \pm 2.2$ & $11.8 \pm 1.4$ & $20.1 \pm 4.0$ \\
\hline & 3 & $17.9 \pm 2.9$ & $15.9 \pm 2.0$ & $12.6 \pm 2.1$ & $17.4 \pm 2.8$ & $49.1 \pm 9.1$ & $29.1 \pm 3.6$ & $27.9 \pm 3.1$ & $44.0 \pm 8.1$ \\
\hline & 10 & $11.6 \pm 2.6$ & $10.6 \pm 2.2$ & $10.3 \pm 1.5$ & $6.9 \pm 1.5$ & $24.3 \pm 2.7$ & $19.6 \pm 4.4$ & $11.2 \pm 3.4$ & $12.2 \pm 4.6$ \\
\hline & 12 & $13.6 \pm 3.0$ & $13.9 \pm 1.0$ & $16.4 \pm 2.7$ & $12.8 \pm 1.4$ & $47.0 \pm 3.6$ & $28.7 \pm 3.8$ & $23.7 \pm 6.3$ & $25.7 \pm 3.2$ \\
\hline & 15 & $43.4 \pm 2.5$ & $53.6 \pm 4.3$ & $50.4 \pm 3.0$ & $44.6 \pm 4.6$ & $12.8 \pm 3.0$ & $14.6 \pm 3.3$ & $14.0 \pm 1.9$ & $12.6 \pm 2.9$ \\
\hline
\end{tabular}


Hydrobiidae
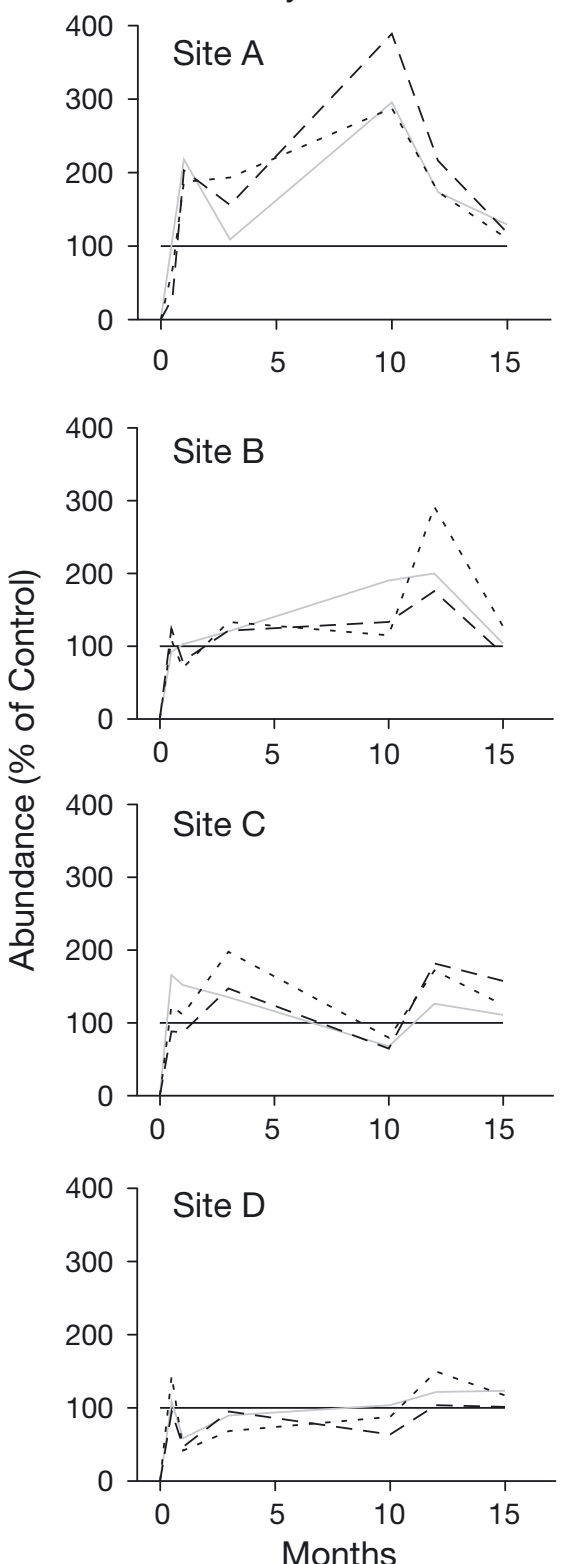

Oligochaeta
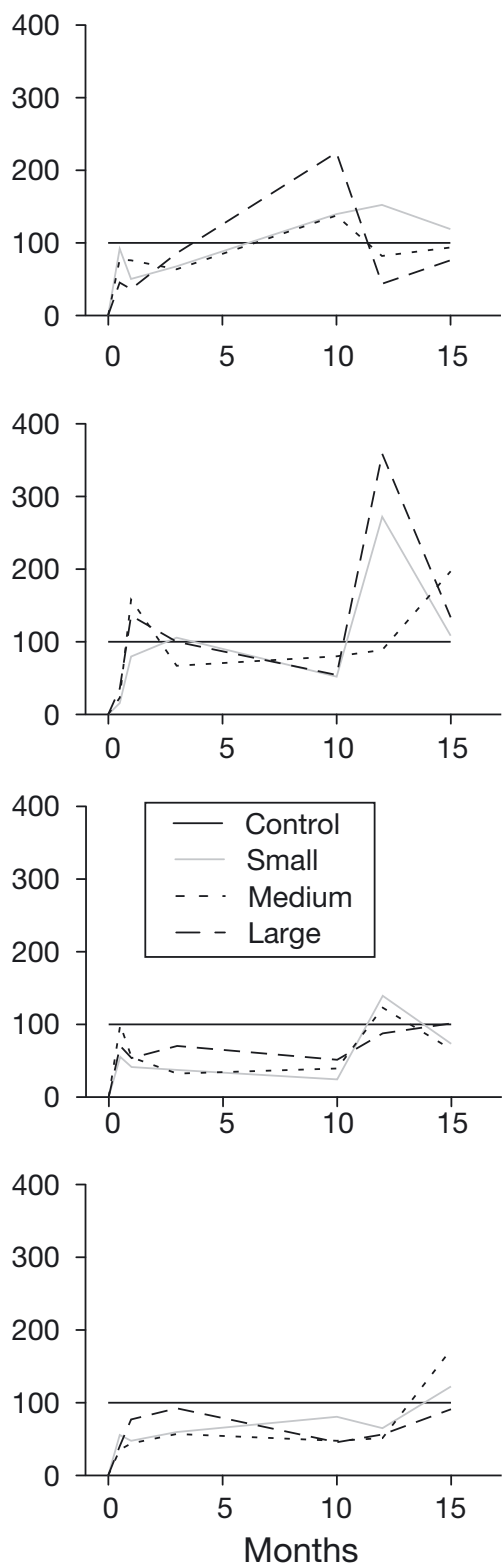

was $198,137,127$ and $92 \%$ of the Control abundance at Sites A, B, C and D, respectively, i.e. the mudsnails exhibited a decreasing opportunistic response with increasing exposure. Overall, the highest abundances of Hydrobiidae at Site A were found in the Large and Medium plots, with the persistence of the opportunistic response increasing with scale. At the other sites the differences between Small, Medium and Large plots were relatively small for Hydrobiidae.

Oligochaeta did not exhibit a strong opportunistic response, and at the more exposed sites, remained below Control levels until $1 \mathrm{yr}$ after the disturbance (Fig. 2). Averaged over all the disturbed treatments and 1 to 15 mo of recovery, the abundance of Oligochaeta in the disturbed treatments was 97, 132, 67 and $74 \%$ of the Control abundance at Sites A, B, C and D, respectively, i.e. the recovery of the infaunal Oligochaeta was clearly delayed compared with the epifaunal Hydrobiidae. Again, the effect of the scale of disturbance was minor. No significant correlation was found between abundances of Hydrobiidae and Oligochaeta in any of the treatments, at any site or any time ( $p>0.05)$.

\section{Variance-to-mean ratios, patchiness and aggregation}

Variance-to-mean ratios of the abundances of Hydrobiidae and Oligochaeta were calculated for each plot (3 replicate cores) and the average of these was plotted for each treatment over time (Fig. 3). Hydrobiidae had highly aggregated patterns (variance-to-mean ratio $\gg 1$ ) in the disturbed treatments at Site A, where the mudsnails exhibited opportunistic responses. Ratios were generally lower in

apparent (Table 3). Hydrobiidae rapidly colonised disturbed plots at all sites. In addition, they exhibited opportunistic responses to the disturbance, which were most pronounced at the most sheltered site (Site A) and then gradually disappeared towards the most exposed site (Site D) (Fig. 2). At Site A, Hydrobiidae exhibited an opportunistic overshoot of up to $400 \%$ (cf. Control and Large plot densities). Averaged over all the disturbed treatments and 1 to 15 mo of recovery, the abundance of Hydrobiidae in the disturbed treatments the Control plots throughout the 15 mo experiment. Similar patterns were found at Site B. These patterns changed when moving towards the more exposed sites. At Site C differences between treatments were smaller (except for the last sampling occasion) and, in contrast to the 2 more sheltered sites, the mudsnails were comparatively more aggregated in the Control plots compared to the disturbed plots at Site D. This indicates that broader-scale physical factors, i.e. waves, currents and sediment transport, resulted in a more 
Table 3. Significance of Site, Treatment, Time within Site and interaction effects on the abundance of Hydrobiidae and Oligochaeta (generalised linear model)

\begin{tabular}{|lccc|}
\hline Factor & $\mathrm{df}$ & $\chi^{2}$ & $\mathrm{p}$ \\
\hline Hydrobiidae & & & \\
Site & 3 & 1655.24 & 0.0001 \\
Treatment & 3 & 165.28 & 0.0001 \\
Time(Site) & 20 & 61184.40 & 0.0001 \\
Site $\times$ Treatment & 9 & 407.47 & 0.0001 \\
Treatment $\times$ Time(Site) & 60 & 3424.16 & 0.0001 \\
Oligochaeta & & & \\
Site & 3 & 14353.11 & 0.0001 \\
Treatment & 3 & 3504.02 & 0.0001 \\
Time $($ Site) & 20 & 20381.74 & 0.0001 \\
Site $\times$ Treatment & 9 & 835.44 & 0.0001 \\
Treatment $\times$ Time(Site) & 60 & 9585.27 & 0.0001 \\
& & & \\
\hline
\end{tabular}

\section{Hydrobiidae}
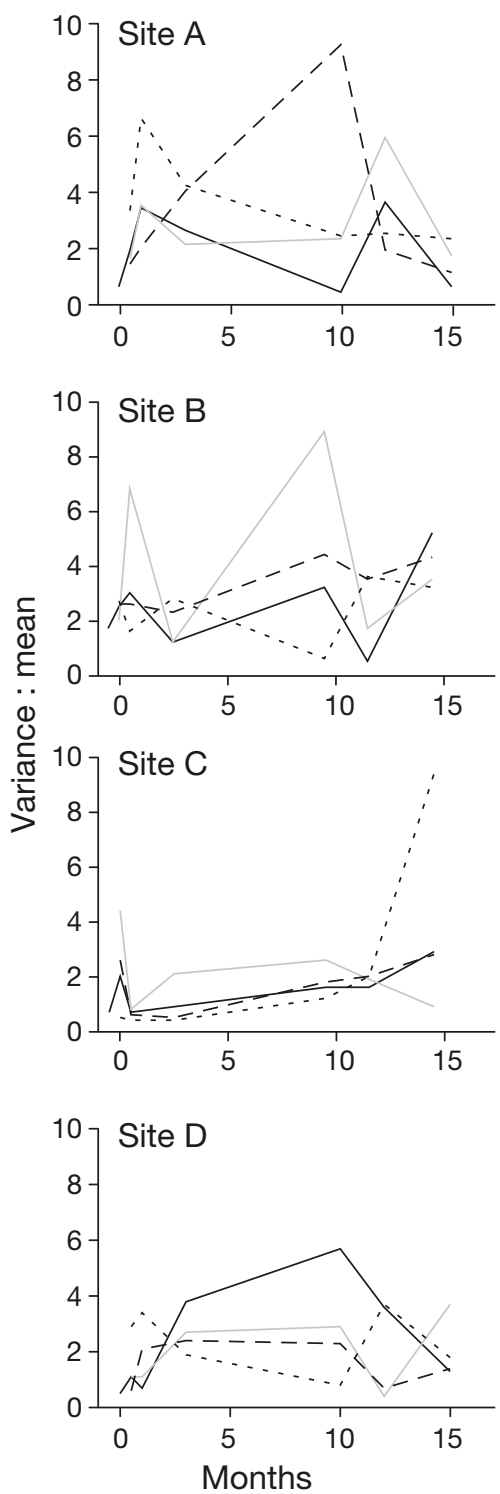

homogeneous recolonisation of the disturbed plots at Sites C and D compared to the more sheltered Sites A and B.

Oligochaeta exhibited contrasting patterns, with the lowest levels of aggregation at Site A and then clearly higher levels of aggregation and stronger differences between treatments over time towards Site D. No consistent differences between treatments were observed, indicating that factors other than those directly related to wind-wave exposure were more important in driving spatial patterns in this infaunal group compared with the epifaunal Hydrobiidae.

\section{Size frequency distribution of Hydrobiidae}

The size frequency distribution of Hydrobiidae was assessed in Control and Large plots for the extremes on the exposure gradient, i.e. the most sheltered (Site A) and the most exposed site (Site D). These 2 sites had similar levels of sediment chl $a$, but contrasting grain size (Table 1). Size frequency distributions differed between treatments and between sites (Fig. 4). After 1 mo, patterns were similar at both sites, with a dominance of smaller size classes overall and very few larger individuals in the Large plots (Kolmogorov-Smirnov tests, differences between Control and Large plots: Site A: $D=0.254, \mathrm{p}$ $=0.007$; Site $\mathrm{D}: D=0.191, \mathrm{p}=0.065)$. For example, at Site A $78 \%$ of the individuals in the Control plots were $<1.2 \mathrm{~mm}$, whereas in the Large plots $97 \%$ were $<1.2 \mathrm{~mm}$. Corresponding values for Site D were $74 \%$ and $87 \%$ in Control and Large plots, respectively. After $3 \mathrm{mo}$, the dominance by smaller size classes persisted at Site A, although at this time no significant difference between Control and Large plots was detected $(D=$ $0.113, p=0.219$ ). At Site $D$, however, the size structure had become more even in both Control and Large plots (Fig. 4), but again with no significant difference between the treatments $(D=0.133, \mathrm{p}=0.136)$. Size patterns in Small and Medium plots mirrored the Large plots at both sites (data not

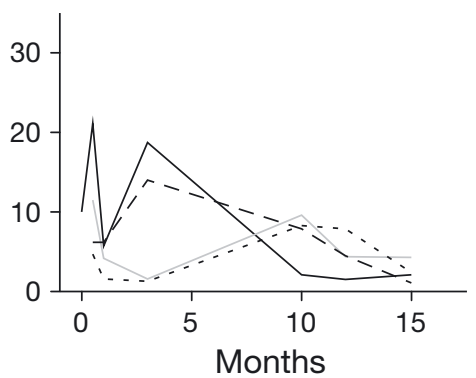

Fig. 3. Variance-to-mean ratios of Hydrobiidae (left panels) and Oligochaeta (right panels) at Sites A to D (top to bottom panels) in different treatments over time after disturbance $(0=$ end of July). Note the different scales for Hydrobiidae and Oligochaeta 

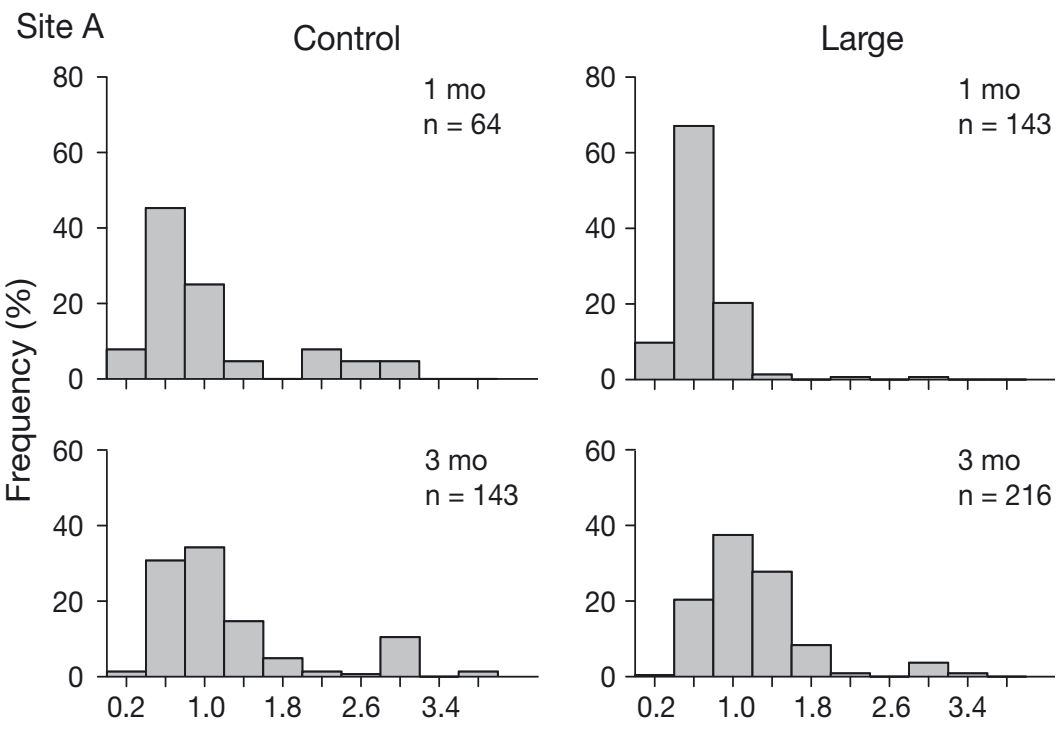

by results from 1 and 3 mo after disturbance (Fig. 5). At Site A relative dispersal rates for Hydrobiidae were higher in Control compared with Large plots (2-way ANOVA: Treatment: $F_{1,12}=15.45, \mathrm{p}=0.0020$; Time: $F_{1,12}=0.54, \mathrm{p}=0.4734$; Interaction: $F_{1,12}=$ 1.15, $\mathrm{p}=0.3041)$. The lower dispersal over Large plots was most likely due to less foraging and more time spent feeding on the abundant microphytobenthos (visibly greener sediment in the disturbed plots). Correspondingly, it is likely that relatively more Hydrobiidae in the Control plots actively crawled into the traps in search of food. This difference between Control and Large plots decreased over time and was not significant at 3 mo ( $p>0.05)$. Interestingly, the low relative dispersal rates of Hydrobiidae in the Large plots at Site A corresponded with opportunistic responses (i.e. high abundances) in
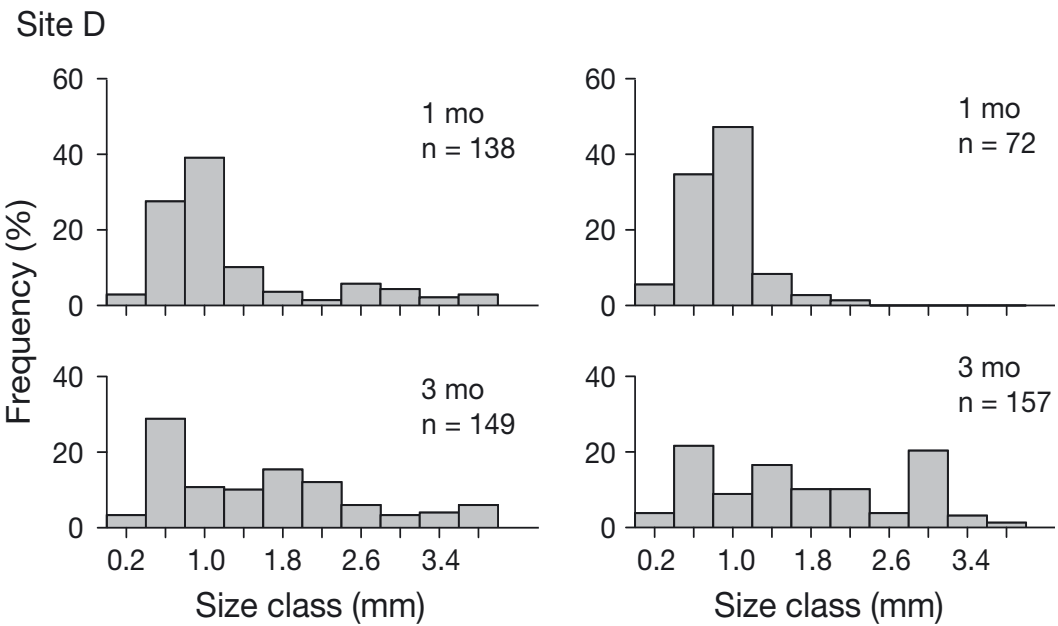

Fig. 4. Size frequency distribution (\%) of Hydrobiidae in Control (left panels) and Large (right panels) plots 1 mo and 3 mo after disturbance at the most sheltered (Site A, top 4 panels) and the most exposed site (Site D, lower 4 panels). The $3.8 \mathrm{~mm}$ size class includes all mudsnails $>3.8 \mathrm{~mm}$ shell length the Large plots at both 1 and 3 mo. Similar patterns were observed at Site B (Treatment: $F_{1,12}=7.59, \mathrm{p}=0.0176$; Time: $F_{1,12}=3.07, \mathrm{p}=$ 0.1054; Interaction: $F_{1,12}=5.53, \mathrm{p}=0.0366$ ). Also at Sites C and D, relative dispersal rates of Hydrobiidae were higher in Control compared with Large plots at $1 \mathrm{mo}$, with the difference decreasing at $3 \mathrm{mo}$, but these differences were not significant ( $p>0.05$ ).

Relative dispersal rates for Oligochaeta were generally lower, with no consistent pattern between sites or over time (Fig. 5). Overall relative dispersal at Site $\mathrm{A}$ was higher at 1 mo than at 3 mo (2-way ANOVA: Treatment: $\mathrm{p}=0.4712$; Time: $\mathrm{p}=0.0348$; Interaction: $p=0.5608$ ), but no significant differences between treatments were observed at any of the sites. Nevertheless, in contrast to Hydrobiidae, relative dispersal in Oligochaeta was often higher (although not signif-

shown). The size distribution of Hydrobiidae in Control plots differed between the 2 sites at both 1 and 3 mo (1 mo: $D=0.250, \mathrm{p}=0.009$; 3 mo: $D=0.281$, $\mathrm{p}<0.0001$ ). No significant differences between treatments were found at either site at any of the subsequent sampling occasions ( $p>0.05)$.

\section{Relative dispersal rates}

Differences in dispersal potential can help explain differences in recovery patterns between taxa. Relative dispersal rates estimated with bedload traps (ind. trap ${ }^{-1}$ $\mathrm{d}^{-1}$ ind. core ${ }^{-1}$ ) were in general higher in Hydrobiidae compared with Oligochaeta, here again exemplified icantly) in Large plots compared with Control plots, suggesting fundamentally different response patterns between the 2 taxonomic groups. Since the number of traps per site was low (for logistical reasons), the power to detect significant differences was also low, but the results are nevertheless useful for helping to understand recovery patterns.

\section{Stable isotopes of mudsnails and sediment}

Stable isotopes of Hydrobia ulvae and surface sediment were measured in different plots at Site A during the first 3 mo of the experiment. No significant trends between treatments or over time were found for $\delta^{13} \mathrm{C}$ in 


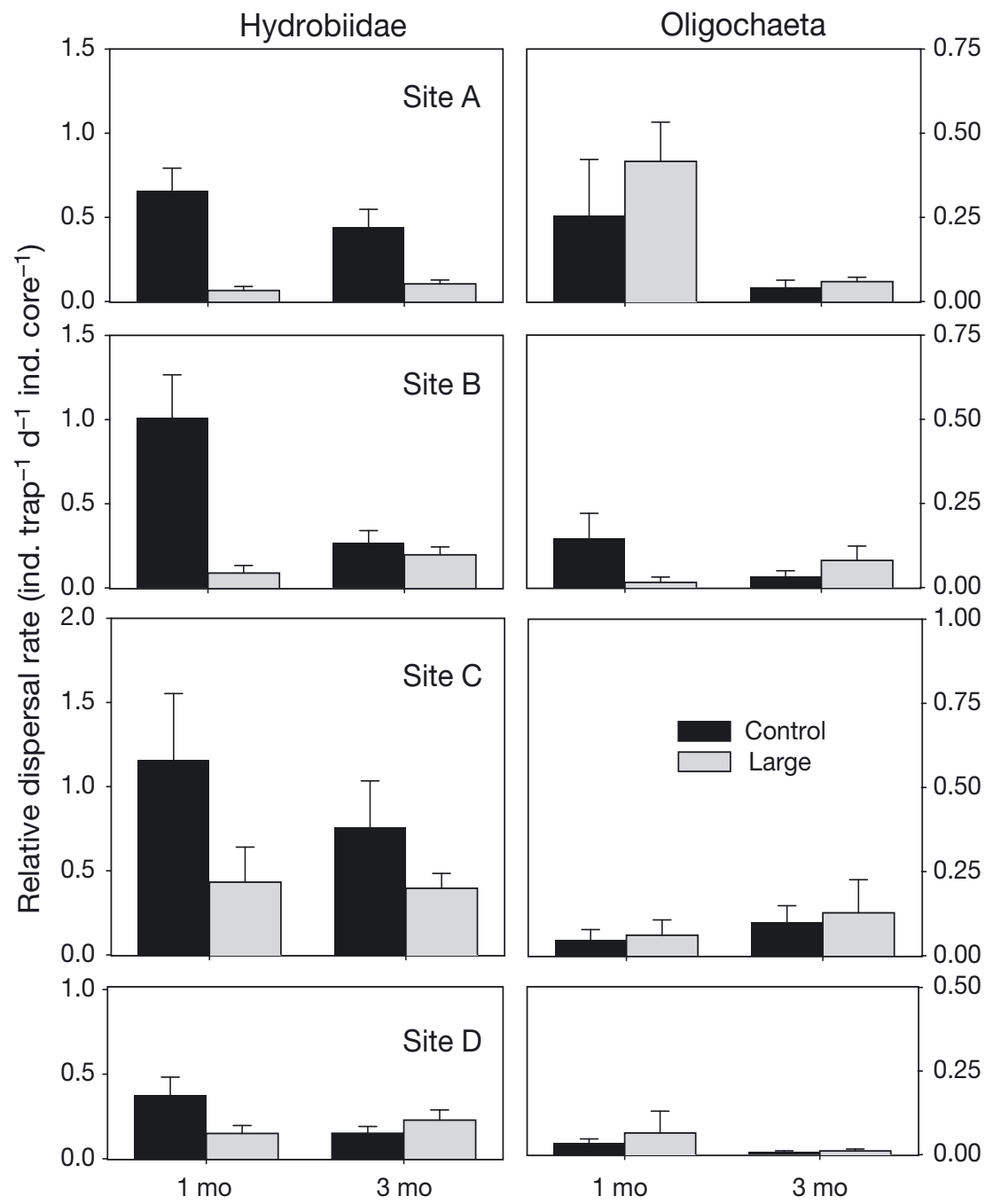

Fig. 5. Relative dispersal rates of Hydrobiidae (left panels) and Oligochaeta (right panels) at Sites A to D (top to bottom panels) in Control $(\mathrm{n}=5)$ and Large ( $\mathrm{n}=3$ ) plots $1 \mathrm{mo}$ and 3 mo after disturbance. Note the different scales for Hydrobiidae and Oligochaeta

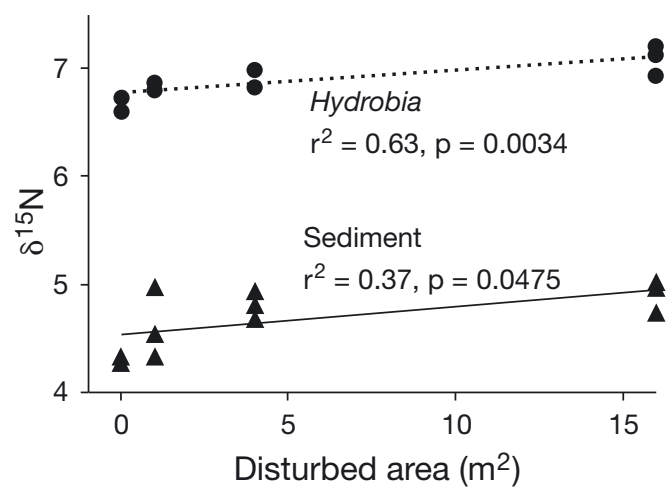

Fig. 6. Stable isotope signatures $\left(\delta^{15} \mathrm{~N}\right)$ in Hydrobia ulvae $(\bullet)$ and surface sediment $(\mathbf{\Lambda})$ across different-sized disturbed plots at Site A, the most sheltered site, 3 mo after disturbance. Results of linear regression analyses are reported either $H$. ulvae or sediment, with average $\delta^{13} \mathrm{C}$ values of $-20.7 \pm 0.5$ and -22.3 \pm 0.4 , respectively. Differences between treatments and over time were small for both $H$. ulvae and sediment also for $\delta^{15} \mathrm{~N}$. However, a significant trend of slightly higher $\delta^{15} \mathrm{~N}$ in both $H$. ulvae and sediment in the disturbed plots was found after 3 mo (Fig. 6), corresponding to the visual observations of stronger microalgal growth in the disturbed plots. The slightly higher $\delta^{15} \mathrm{~N}$ of the sediment in the disturbed plots indicates a greater proportion of recycled nitrogen in the disturbed plots and this was mirrored in the $\delta^{15} \mathrm{~N}$ of the $H$. ulvae, indicating that the mudsnails indeed are staying and feeding inside the disturbed plots, likely benefiting from the abundant microphytobenthos on the sediment surface (Fig. 6).

\section{DISCUSSION}

Disturbance events in coastal ecosystems are increasing in spatial and temporal extent, and the integrity of seafloor ecosystems is dependent on the inherent ability of the benthic communities to recover from these disturbances. We used a subtidal disturbance-recovery experiment with the aim of identifying the context-dependency and relative importance of the underlying mechanisms in the recovery process. Our results showed that recovery patterns after disturbance were indeed highly context-dependent, as patterns were both site- and taxon-specific (Fig. 7).

We predicted that recovery would be fastest at the most exposed site, with hydrodynamic forcing (waves, currents) aiding recolonisation. Contrary to predictions, however, initial increases (after 1 mo of recovery) in abundances and overall recolonisation rates were faster at the more sheltered sites, particularly for the surface-dwelling Hydrobiidae. This was likely due to high microphytobenthic production (resulting from disturbance-induced release of sediment nutrients), which to a greater extent remained in the disturbed plots at the sheltered sites, where it was efficiently colonised particularly by actively crawling Hydrobiidae. This release of resources thus facilitated the initial recolonisation and even produced a long-lasting overshoot in abundances compared with the Control 

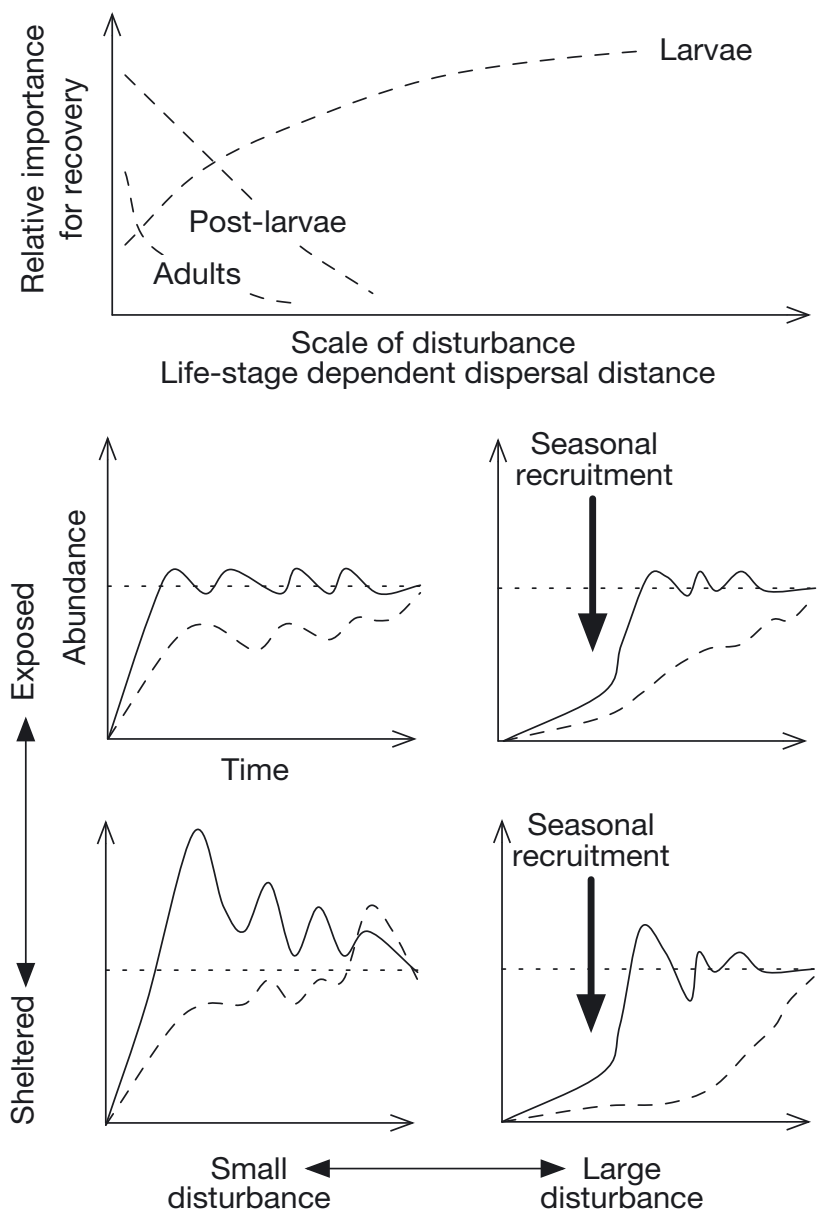

Fig. 7. Conceptual model of the relative importance of adults, post-larvae and larvae for the recovery dynamics after increasing spatial scales of disturbance (top panel). As the scale of disturbance exceeds post-larval dispersal ranges, the recovery becomes dependent on seasonal recruitment. Hypothetical recovery trajectories after disturbances in sheltered and exposed systems with low functional diversity (lower 4 panels) are exemplified by a mobile opportunistic species with planktonic larvae $(-)$ and a sedentary brooding species $(---)$. A normalised control community is shown (....)

plots. Importantly, such an overshoot does not necessarily imply recovery, but rather is indicative of a prolonged disturbance effect (Norkko et al. 2006b, Van Colen et al. 2010). It is likely that these taxa would recover faster at more exposed sites if the scale of disturbance exceeded the range of post-larval dispersal.

In line with our predictions, the epifaunal Hydrobiidae recovered faster than the infaunal Oligochaeta, which can be attributed to the generally greater mobility of epifaunal taxa compared with infaunal taxa, and the tendency of Hydrobiidae to rapidly aggregate around patches of food and utilise abundant microphytobenthos (Norkko \& Bonsdorff 1996a, Herman et al. 2000, Norkko et al. 2000). In a short-term experiment ( $5 \mathrm{~d}$ of recovery after drift algal disturbance, $0.25 \mathrm{~m}^{2}$ plots), Norkko \& Bonsdorff (1996a) also found that Hydrobiidae abun- dances recovered faster than Oligochaeta and also increased above abundances in ambient undisturbed areas, highlighting the differences in active versus passive dispersal/recolonisation between these 2 groups. The present experiment highlights that these are not transient patterns but may persist for over a year. Importantly, they may also be highly site-dependent. The relative dispersal rates also indicated that Hydrobiidae were more mobile than Oligochaeta. Many species of Oligochaeta reproduce asexually, lack a planktonic larval stage or are brooders, although some adults may migrate by swimming in response to resource depletion (Nilsson et al. 2000). This reproductive behaviour could also partly explain the slower recovery in Oligochaeta, but the rapid influx of Hydrobiidae may have interfered with the establishment of juvenile Oligochaeta on the sediment. Oligochaeta recovery may, however, be rapid in patches where egg capsules survive anoxic events and hatch (Norkko \& Bonsdorff 1996a). Our experiment did not start until just after the main seasonal recruitment peak, so post-larval dispersal was likely the main mechanism of recolonisation for both Oligochaeta and Hydrobiidae, until possible larval recruitment the following year. The timing of opening up our experimental plots to recolonisation also coincided with the seasonal maximum extent of drifting algal mats in the northern Baltic (Norkko \& Bonsdorff 1996b). While the temporal variability of surface deposit feeders may also be greater than for subsurface feeders due to differences in the stability of food resources (Levinton \& Kelaher 2004), these effects may be site-dependent, as indicated by the high degree of change in spatial aggregation over time of Hydrobiidae compared with Oligochaeta at the most sheltered site, while at the most exposed site we found the opposite pattern: Oligochaeta exhibited the lowest levels of aggregation at the most sheltered site and then more aggregation and stronger differences between treatments over time towards the more exposed sites (Fig. 3).

Interestingly, the Hydrobiidae exhibited marked opportunistic responses to the disturbance, which lasted for a whole year, particularly in the largest disturbed plots at the most sheltered site. The size structure analyses of Hydrobiidae showed that the opportunistic response was mainly driven by juveniles. However, for the population to be considered fully recovered, the proportion of adult individuals needs to increase in the recovering plots, as Cardoso et al. (2005) reported for Hydrobia ulvae, and which in the present study was observed after 3 mo of recovery (Fig. 4). Norkko et al. (2006b) found similar scaledependent opportunistic responses to disturbance by the amphipod Corophium volutator in intertidal areas on the Swedish west coast, also in connection with blooms of microphytobenthos in the disturbed areas. 
Although the sediment was visibly greener in our disturbed plots, we were not able to quantitatively link the faunal responses to changes in sediment chl $a_{\text {, }}$ most likely due to the rather crude method of chlorophyll sampling, i.e. integrating over the top $1 \mathrm{~cm}$, instead of targeting only the sediment surface. The lack of strong disturbance effects in the stable isotope signatures of $H$. ulvae and sediment indicates that the opportunistic patterns observed at Site A were not due to differences in the source of food between treatments, although the isotope results did indicate a greater proportion of recycled nitrogen in the disturbed plots. It is therefore likely that either increased food availability or release from competition or predation facilitated the opportunistic response, and that the mudsnails therefore preferentially spent more time in the disturbed plots, as also indicated by our relative dispersal rate patterns. Such interactions between localised resource inputs and mobile consumers may explain high spatial variability in the community (Levinton \& Kelaher 2004).

Our findings thus highlight the importance of conducting relevant field experiments across environments, in order to aid our capability to predict community changes. Predicting abrupt change can be about defining threshold conditions in environmental stressors, but it is also about understanding the interactions between taxa that influence community dynamics. Our results also highlight the importance of including taxon-specific responses, and understanding naturalhistory characteristics of populations, when assessing the resilience of different benthic communities (Fig. 7). As the Hydrobiidae and Oligochaeta in this area are amongst the numerically dominant groups, their population dynamics and recovery rates and patterns are of importance for the trophic functioning of the coastal ecosystem. In addition, this system lacks large habitat modifiers or ecosystem engineers, which could potentially modulate the community response to disturbance (Zajac et al. 1998, Norkko et al. 2006a, 2006b, Van Colen et al. 2010).

Coastal marine ecosystems are affected by a combination of multiple human impacts (Costanza et al. 1997, Lotze et al. 2006) and one pressing issue is defining how close to a threshold a system is (Thrush et al. 2009). The multiple stressors influence species-habitat relationships, which in turn change along natural environmental gradients. Therefore location $\times$ treatment interactions are common in experimental studies. Although experiments for logistical reasons are often conducted in one location only, this significantly limits the generality of the findings (Thrush et al. 2000). By using locations arrayed along relevant environmental gradients, however, it is possible to quantify why these locations respond differently (Hewitt et al. 2007). It is also necessary to consider which spatial scales the different factors involved in the recovery process operate and interact over (Zajac et al. 1998). Disturbance may release resources, which have transient or longerlasting effects on the communities depending on the different species' abilities to exploit them (Kelaher \& Levinton 2003, Holt 2008, Van Colen et al. 2010). Disturbance also creates patchy communities, in both time and space, with threshold effects likely when the scale of disturbance exceeds post-settlement dispersal ranges of the key species (Fig. 7). Although some scale-dependent recovery patterns were observed in our experiments for the bivalve Macoma balthica (A. Norkko et al. unpubl.) for example, no long-lasting threshold responses over the spatial scales of disturbance we studied here were apparent for Hydrobiidae or Oligochaeta, most likely because the spatial extent of the disturbance was still relatively limited and within the potential range of post-larval, juvenile or adult dispersal along the sediment surface (either active movement or with the sediment bedload transport). A threshold or shift in mechanisms of recovery will therefore likely occur when the disturbance exceeds post-larval dispersal potential and becomes dependent on seasonal recruitment of planktonic larvae (Fig. 7). In line with our predictions, we found that the importance of small-scale, local and biological factors in the recovery process was greater at the sheltered sites, while there was a switch to greater importance of physical, broader-scale, regional factors at the more exposed sites (e.g. waves, currents). A sudden shift in the interactions between these factors was however not identified, as the factors changed gradually along the environmental exposure gradient. Context-dependency and generality are often viewed as opposing forces, but incorporating the shifts in the relative importance of different biological and physical factors in driving recovery patterns and understanding the underlying mechanisms of context-dependent patterns will help inform our understanding and prediction of generality and potential thresholds in disturbance-recovery dynamics.

Thresholds in community structure or functioning are reached when recovery patterns after disturbance are sufficiently perturbed (Thrush et al. 2009). For example, in the Baltic Sea, the low salinity limits the number of species available for recolonisation and due to low functional redundancy, such a species-poor system affected by increasing hypoxia is potentially continuously close to a resilience threshold. Recovery to the same depauperate community after hypoxia may be relatively rapid in a degraded system characterised by small, rapidly growing species (Thrush \& Whitlatch 2001, Troell et al. 2005), and recovery is thus easier to predict in a low-diversity system (Fig. 7). In a more 
diverse system, disturbance may result in dramatic shifts in species composition, as there are greater ranges in life-history characteristics and recolonisation potential. A more diverse system, with overlapping and seemingly redundant functions, does theoretically have an overall greater resilience (Peterson et al. 1998). In both kinds of systems, a slowing rate of recovery may be a sign of declining resilience in the system and may foreshadow an approaching threshold condition and subsequent regime shift (van Nes \& Scheffer 2007).

Information on natural-history characteristics and functional diversity in the communities and gradients in environmental conditions should all be used to make informed predictions about changes in the resilience of coastal ecosystems. Also, the importance of in situ measurements and interdisciplinary field experiments for understanding benthic ecosystem function should be stressed, as the interactions between the fauna, the sediment and the environment are complex and context-dependent, with potential for highly nonlinear responses to environmental change (Norkko et al. 2006b, Van Colen et al. 2010). The challenge is still to move from hindsight to more predictive science (Thrush et al. 2009) and it is clear that modelling efforts will need to include and synthesise information gathered from numerous empirical studies, conducted in a wide range of environments.

Acknowledgements. This study was funded by the Academy of Finland (project numbers 114076 and 110999), the Kone Foundation, the Swedish Cultural Foundation in Finland, the Walter and Andrée de Nottbeck Foundation, and Societas Biologica Fennica Vanamo. The work was supported by FRST C01X0501 and a Marie Curie International Incoming Fellowship to S.F.T. We thank A. Villnäs, A. Jansson, L. Kauppi, J. Lehtonen and G. Funnell for help with fieldwork and laboratory analyses. We thank Tvärminne Zoological Station for providing excellent facilities and support for conducting large-scale field experiments.

\section{LITERATURE CITED}

Cardoso PG, Brandão A, Pardal MA, Raffaelli D, Marques JC (2005) Resilience of Hydrobia ulvae populations to anthropogenic and natural disturbances. Mar Ecol Prog Ser 289: 191-199

Costanza R, d'Agre R, De Groot R, Faber S and others (1997) The value of the world's ecosystem services and natural capital. Nature 387:253-260

> Cowen RK, Sponaugle S (2009) Larval dispersal and marine population connectivity. Annu Rev Mar Sci 1:443-466

Crawley MJ (1993) GLIM for ecologists. Blackwell Scientific, Oxford

> Dauer DM, Simon JL (1976) Habitat expansion among polychaetous annelids repopulating a defaunated marine habitat. Mar Biol 37:169-177

> Dayton PK (2003) The importance of the natural sciences to conservation. Am Nat 162:1-13

> Groffman PM, Baron JS, Blett T, Gold AJ and others (2006) Ecological thresholds: the key to successful environmental management or an important concept with no practical application? Ecosystems 9:1-13

Herman PMJ, Middelburg JJ, Widdows J, Lucas CH, Heip CHR (2000) Stable isotopes as trophic tracers: combining field sampling and manipulative labelling of food resources for macrobenthos. Mar Ecol Prog Ser 204:79-92

Hewitt JE, Thrush SF, Dayton PK, Bonsdorff E (2007) The effect of spatial and temporal heterogeneity on the design and analysis of empirical studies of scale-dependent systems. Am Nat 169:398-408

- Holt RD (2008) Theoretical perspectives on resources pulses. Ecology 89:671-681

Karlson K, Bonsdorff E, Rosenberg R (2007) The impact of benthic macrofauna for nutrient fluxes from Baltic Sea sediments. Ambio 36:161-167

> Kelaher BP, Levinton JS (2003) Variation in detrital enrichment causes spatio-temporal variation in soft-sediment assemblages. Mar Ecol Prog Ser 261:85-97

Levinton J, Kelaher B (2004) Opposing organizing forces of deposit-feeding marine communities. J Exp Mar Biol Ecol 300:65-82

> Lotze HK, Lenihan HS, Bourque BJ, Bradbury RH and others (2006) Depletion, degradation, and recovery potential of estuaries and coastal seas. Science 312:1806-1809

McCullagh P, Nelder JA (1989) Generalised linear models. Chapman \& Hall, London

> Nilsson PG, Levinton JS, Kurdziel JP (2000) Migration of a marine oligochaete: induction of dispersal and microhabitat choice. Mar Ecol Prog Ser 207:89-96

> Norkko A, Bonsdorff E (1996a) Population responses of coastal zoobenthos to stress induced by drifting algal mats. Mar Ecol Prog Ser 140:141-151

Norkko A, Bonsdorff E (1996b) Rapid zoobenthic community responses to accumulations of drifting algae. Mar Ecol Prog Ser 131:143-157

Norkko J, Bonsdorff E, Norkko A (2000) Drifting algal mats as an alternative habitat for benthic invertebrates: species specific responses to a transient resource. J Exp Mar Biol Ecol 248:79-104

Norkko A, Hewitt JE, Thrush SF, Funnell GA (2006a) Conditional outcomes of facilitation by a habitat-modifying subtidal bivalve. Ecology 87:226-234

Norkko A, Rosenberg R, Thrush SF, Whitlatch RB (2006b) Scale- and intensity-dependent disturbance determines the magnitude of opportunistic response. J Exp Mar Biol Ecol 330:195-207

> Pascual M, Guichard F (2005) Criticality and disturbance in spatial ecological systems. Trends Ecol Evol 20:88-95

Pearson TH, Rosenberg R (1978) Macrobenthic succession in relation to organic enrichment and pollution of the marine environment. Oceanogr Mar Biol Annu Rev 16:229-311

> Peterson G, Allen CR, Holling CS (1998) Ecological resilience, biodiversity, and scale. Ecosystems 1:6-18

Sartory DP (1982) Spectrophotometric analysis of chlorophyll $a$ in freshwater phytoplankton. Hydrological Research Institute, Pretoria

Scheffer M, Bascompte J, Brock WA, Brovkin V and others (2009) Early-warning signals for critical transitions. Nature 461:53-59

Swift TL, Hannon SJ (2010) Critical thresholds associated with habitat loss: a review of the concepts, evidence, and applications. Biol Rev Camb Philos Soc 85:35-53

$>$ Thrush SF (1991) Spatial patterns in soft-bottom communities. Trends Ecol Evol 6:75-79

Thrush SF, Whitlatch RB (2001) Recovery dynamics in benthic communities: balancing detail with simplification. Ecol Stud 151:297-316 
Thrush SF, Whitlatch RB, Pridmore RD, Hewitt JE, Cummings VJ, Wilkinson MR (1996) Scale-dependent recolonization: the role of sediment stability in a dynamic sandflat habitat. Ecology 77:2472-2487

Thrush SF, Hewitt JE, Cummings VJ, Green MO, Funnell GA Wilkinson MR (2000) The generality of field experiments: interactions between local and broad-scale processes. Ecology 81:399-415

$>$ Thrush SF, Hewitt JE, Norkko A, Cummings VJ, Funnell GA (2003) Macrobenthic recovery processes following catastrophic sedimentation on estuarine sandflats. Ecol Appl 13:1433-1455

Thrush SF, Hewitt JE, Dayton PD, Coco G and others (2009) Forecasting the limits of resilience: integrating empirical research with theory. Proc Biol Sci 276:3209-3217

Troell M, Pihl L, Rönnbäck P, Wennhage $H$, Söderqvist $T$, Kautsky N (2005) Regime shifts and ecosystem service generation in Swedish coastal soft bottom habitats: when resilience is undesirable. Ecol Soc 10:30. Available at: www.ecologyandsociety.org/vol10/iss1/art30/

Vahtera E, Conley DJ, Gustafsson BG, Kuosa H and others (2007) Internal ecosystem feedbacks enhance nitrogenfixing cyanobacteria blooms and complicate management in the Baltic Sea. Ambio 36:186-194

Submitted: October 30, 2009; Accepted: July 23, 2010
Valanko S, Norkko A, Norkko J (2010) Strategies of postlarval dispersal in non-tidal soft-sediment communities. J Exp Mar Biol Ecol 384:51-60

> Van Colen C, Montserrat F, Vincx M, Herman PMJ, Ysebaert $\mathrm{T}$, Degraer S (2008) Macrobenthic recovery from hypoxia in an estuarine tidal mudflat. Mar Ecol Prog Ser 372:31-42

> Van Colen C, Montserrat F, Vincx M, Herman PMJ, Ysebaert T, Degraer S (2010) Long-term divergent tidal flat benthic community recovery following hypoxia-induced mortality. Mar Pollut Bull 60:178-186

van Nes EH, Scheffer M (2007) Slow recovery from perturbations as a generic indicator of a nearby catastrophic shift. Am Nat 169:738-747

Whitlatch RB, Lohrer AM, Thrush SF, Pridmore RD, Hewitt JE, Cummings VJ, Zajac RN (1998) Scale-dependent benthic recolonization dynamics: life stage-based dispersal and demographic consequences. Hydrobiologia 375-376:217-226

Zajac RN, Whitlatch RB (1982) Responses of estuarine infauna to disturbance. II. Spatial and temporal variation of succession. Mar Ecol Prog Ser 10:15-27

Zajac RN, Whitlatch RB, Thrush SF (1998) Recolonization and succession in soft-sediment infaunal communities: the spatial scale of controlling factors. Hydrobiologia 375-376: $227-240$

Proofs received from author(s): August 17, 2010 